\title{
The Logical Structure of the E-Commerce Platform Design and External Interfaces to Achieve of $\mathrm{O}$ To $\mathrm{O}$
}

\author{
WEI Li-jun \\ Department \\ of Electrical Engineering, \\ Hunan Railway \\ Professional Technology College, Zhuz \\ hou, 412001 \\ GONG Jiang-tao \\ Department \\ of Electrical Engineering, \\ Hunan Railway \\ Professional Technology College, Zhuz \\ hou, 412001
}

\author{
WU Hai-bo \\ Department \\ of Electrical Engineering, \\ Hunan Railway \\ Professional Technology College, Zhuz \\ hou, 412001 \\ CHEN Xin-xi \\ Department \\ of Electrical Engineering, \\ Hunan Railway \\ Professional Technology College, Zhuz \\ hou, 412001
}

\author{
XIAO Liao-liang \\ Department \\ of Electrical Engineering, \\ Hunan Railway \\ Professional Technology College, Zhuz \\ hou, 412001 \\ TANG Dong-mei \\ School of Geosciences and \\ Info-Physics, Central South University, \\ Changsha, 410083
}

\begin{abstract}
Online To Offline, it is a line from online to down, and combine online resources with real economy ,therefore allowing the network to become the real economy to an e-commerce model extends to the virtual world of the "front", different from the B2B - (Business To Business) and B2C (Business to Customer) to become a very popular business model. On the basis of the principle of relational database logical structure design as well as different forms of the external interface of e-commerce platform in the $\mathrm{O} 2 \mathrm{O}$ mode, explore the site structure of the the $\mathbf{O} 20$ business model for life service e-commerce platform is designed to provide a good design ideas.
\end{abstract}

Key words-Online To the Offline; e-commerce platform; logical structure; the realization of the external interface.

\section{INTRODUCTION}

O2O namely Online To Offline, It's a business model means from network to real life, it can fusion and integration the entity economy and the resources on network. The network will be the "reception" of the entity economy extends to the virtual world. So,the business of offline can mining and attract customers online, Consumers can be screened for goods and services online, Obtaining the commodity information,preferential certificate, signed orders, even for payment online, and then to the merchant to enjoy services offline. They share the message of merchant offline to consumers online by discount ( group purchase, such as GroupOn ), providing information, services ( scheduled, such as Opentable ) and other means, and then, the consumers online will become their customers offline. For consumers, it is a " discovery" mechanism to get the most convenient and affordable.

This paper introduces the theory of relational database firstly, On this foundation, puts forward the train of thought of life and service $\mathrm{O} 2 \mathrm{O}$ e-commerce platform logic structure design, and then designed of $\mathrm{O} 2 \mathrm{O}$ e- commerce platform for the external interface

implementation detailed, realizated website architecture thought preliminary, It is a good try of $\mathrm{O} 2 \mathrm{O}$ e-commerce platform construction.

\section{THE DESIGN PRINCIPLE OF RELATIONAL DATABASE}

The relational database is the data in the database is stored in rows and columns, In order to understand for the user, this a series of row and column known as table, A set of tables to form a database.In a relational database, all data items in relationship to the organization, The connection between tables called relationship, Through the relationship, we can more flexibly representation and manipulation of data. In addition, the user can conveniently use the query to retrieve data from a database, A query is a SELECT statement, the statement is used to specify the database rows and columns.

The relational databases typically includes a client application program ( Client ), a database server, database component, It is to support the relational model database system. Relational data structure, relation operation set and integrity constraints formed a relationship model

\section{SYSTEM DATABASE LOGICAL STRUCTURE DESIGN OF O2O E-COMMERCE PLATFORM}

The system database of e- commerce platform design principle is a relational database, It has very high reliability, long term operation of rarely occurring fault.In the early versions of the database engine for stopping and starting of the management operation can executed in Engine Implementation now. Thus it increases the availability. It must review any user access to the database, It can also encrypted all the data transmitted application program and the database, using secure socket layer ( SSL ) encryption approach, 
Therefore, this system has high reliability security and scalability.

Electronic commerce group purchase platform as an example, on the platform of $\mathrm{O} 2 \mathrm{O}$ electron business affairs in the " members table " was designed, its structure is shown in figure 1 .

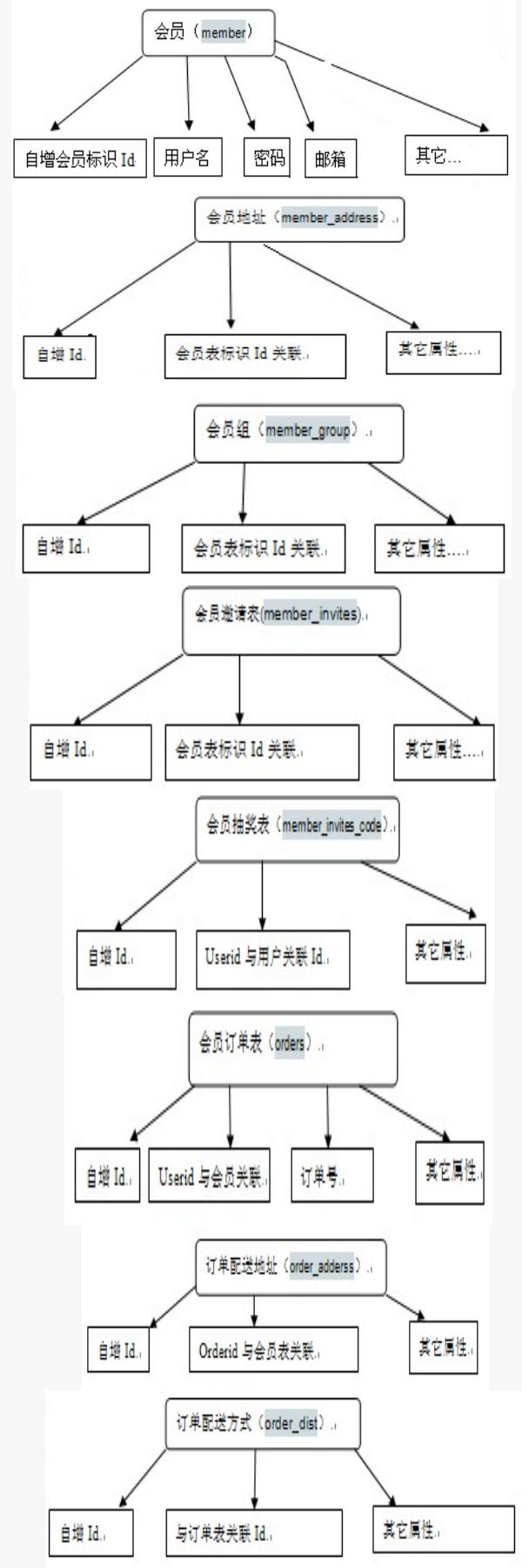

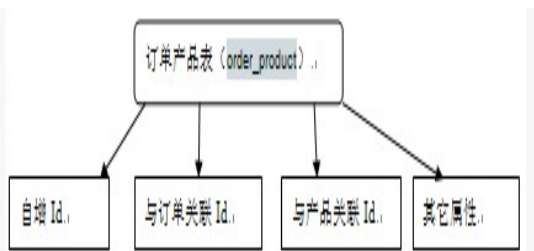
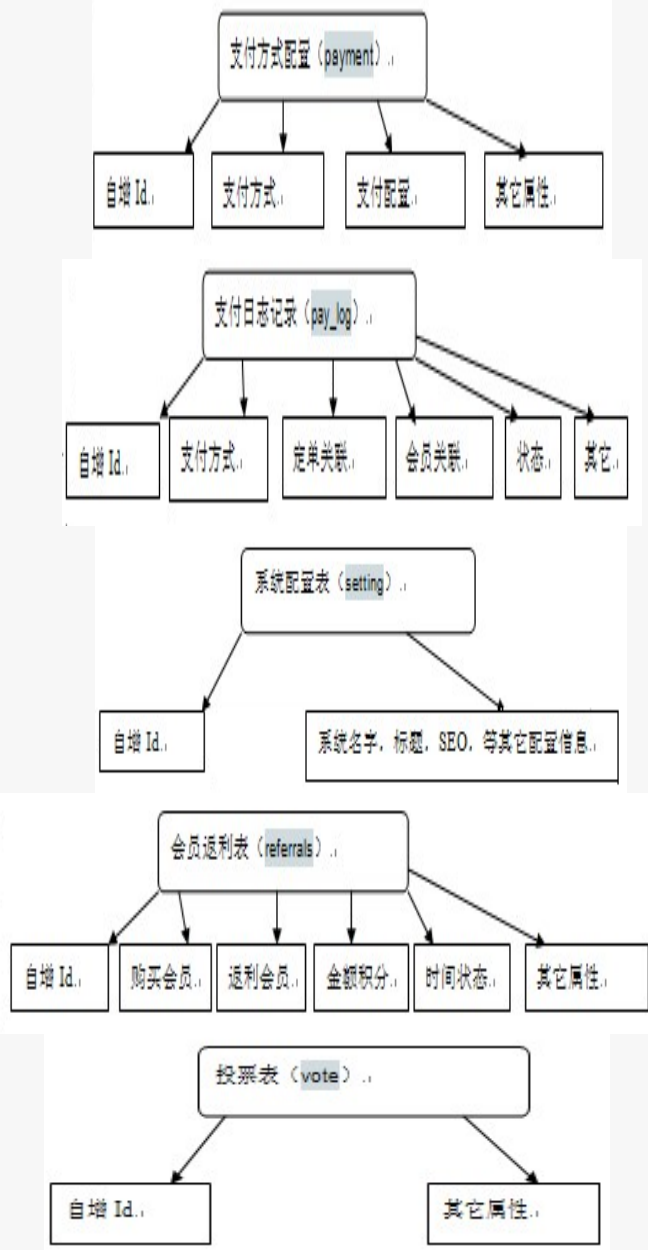

Fig 1: Member table structure diagram

The table includes: Member login interface table, member of group address table membership invitation list, members raffle table, membership table orders, delivery address table orders delivery table, order products table, payment allocation table, pay log table, system settings table and voting member rebate and so on.

Each of the other portion of the sheet structure is not list one by one. the final form the relationships of tables and tables is shown in figure 2. 


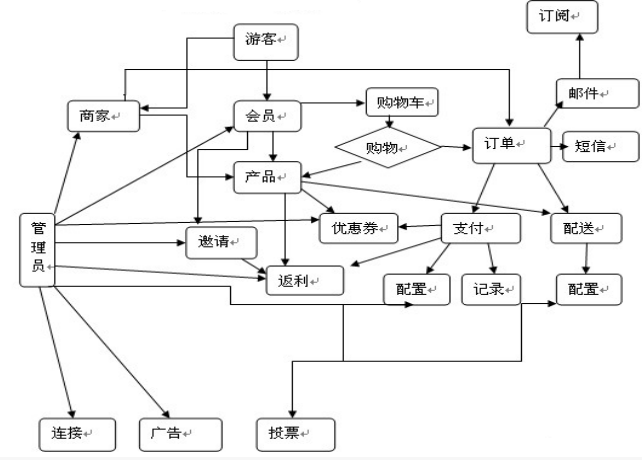

Fig2: Relationships of tables and tables

\section{O2O E-COMMERCE PLATFORM FOR THE EXTERNAL} INTERFACE

External interface implementation in two ways: The 360 format and the 800 format. This design has been used in the 360 format to design and realize. The concrete design code is as follows:

$<$ data $>$

$<$ site_name $>$ site_name $</$ site_name $>$

$<$ !-- site_name, [must fill in] -->

$<$ !-- [Be careful]- Development of the interface before reading, please write them following the code completely, Do not define the node name by yourself. -->

$<$ goodsdata $>$

$<$ goods id="1">

$<$ !-- API ID ranking, to the 1.2.3.4 arrangement, a group purchase site products ID, id=1, default mainly pushed commodity.

[must fill in]-->

$<$ city_name> National </city_name>

$<$ !_city_name ( city name does not need to attached to the provincial, city, District, county and other word, if it is a nationwide, fill the: National, [must fill in] -->

$<$ site_url>http:// site_url /</site_url>

$<$ !-- Web site address,[must fill in] -- $>$

$<$ title $>$ Ming 美发沙龙 $</$ title $>$

$<$ !-- The short title of goods, 20 Chinese characters., [must fill in]-->

<goods_url>http://Website domain name/deal.php?typeid=3\&id=

$40<$ /goods_url $>$

$<$ !-- goods_url, [must fill in] -->

$<$ desc $>$
仅 2 元！原价 58 元到店消费另付 26 元，即可享受 Ming 美发沙龙创意洗剪吹套组一次！洗、剪、吹+头部按摩！男 女不限, 长短发不限。敏锐的时尚触觉, 给你独特的创意 造型, 这个季节, 你才是那道美丽的风景 Ming 一流的环 境，一流的技术！

$</$ desc $>$

$<$ !-- Description of goods, merchandise website for a complete description

, [must fill in] -->

$<$ class $>$ Catering food $</$ class $>$

$<$ !--

Commodity category, must from the following classification in the selection of a: " catering food, entertainment, beauty care, shopping, coupon ticket, other ", not independent fill categories, [must fill in]

$-->$

$<!--$

Add classification aims to provide a better user experience group purchase group purchase, product classification partners, please try to provide accurate classification, the classification error, will not be able to capture interface data

$-->$

$<$ img_url $>$

http://

Website

domain name/attached/2011-11/201211291219576597.jpeg

$</$ img_url $>$

$<!--$

Commercial address, in order to make the page more beautiful, now provides the picture format is.Jpg, size of $270 * 160$ pixels ( or ratio ), picture not stroke, avoid uploading pictures, [must fill in]

$-->$

$<$ original_price $>2.00<$ /original_price $>$

$<$ !-- The original, floating-point type, unit: Yuan, [must fill in] $-->$

$<$ sale_price $>2.00<$ sale_price $>$

$<$ !-- Price, floating-point type, unit: yuan, , [must fill in] -->

$<$ sale_rate $>48<$ /sale_rate $>$

$<$ !-- Discount, floating-point type, unit: yuan,[must fill in] -- $>$

$<$ sales_num $>48<$ /sales_num $>$

$<$ !- The number of buier,[must fill in]-->

<start_time $>20111129121900</$ start_time $>$

$<$ !-- Group purchase start time, date, format:YYYYMMDDHHMMSS, [must fill in] --> 
<close_time $>20111228121900</$ close_time $>$

$<$ !-- Group purchase over time, date, format:YYYYMMDDHHMMSS, [must fill in] -->

$<!--$

The following information for group purchase business information, business address may support only one address, please choose, each node label do not appear, newline, if the group purchase merchandise for mail order, related items can be empty, a mail-order category is required

$-->$

$<$ merchant_name $>$ Ming 美发沙龙 $</$ merchant_name $>$

$<$ !-- Business name, if the group purchase merchandise for mail order, can be empty

[must fill in] -->

$<$ merchant_tel/ $>$

$<$ !-- telephone number, [must fill in] -->

$<$ spend_start_time $>20121130000000</$ spend_start_time $>$

$<$ !-- Consumption starting time, date ,

YYYYMMDDHHMMSS, If the group purchase merchandise for mail order, can be empty,[must fill in] -->

<spend_close_time>20120130000000</spend_close_time>

$<$ !-- The consumption end time, date ,

YYYYMMDDHHMMSS, If the group purchase merchandise for mail order, can be empty,[must fill in] -->

$<$ merchant_addr> Hunan province Zhuzhou city Zhuzhou department store on the first floor of the building, $<$ /merchant_addr $>$

$<$ !-- If the group purchase merchandise for mail order, can be empty

, [do not must fill in] -->

$<$ hot_area/>

$<$ !-- Popular shopping district, [do not must fill in] -->

$<$ longitude/ $>$

$<$ !-- Longitude , [do not must fill in] -->

$<$ latitude/>

$<$ !-- Latitude, [do not must fill in] -->
$</$ goods $>$

$</$ data $>$

The actual interface part as shown in figure 3.

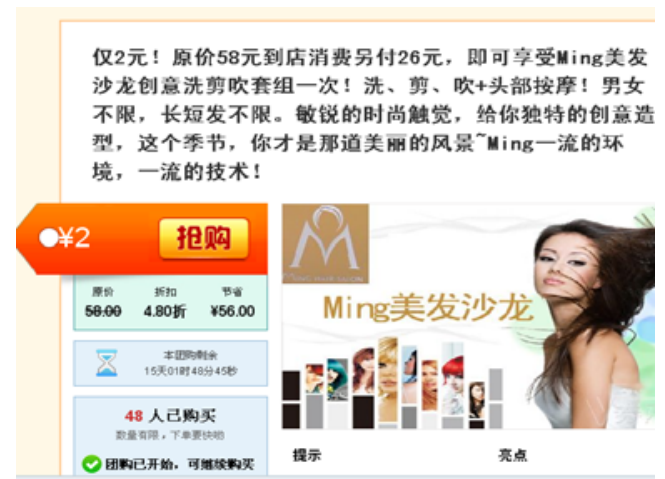

Fig 3 The external interface diagram

\section{CONCLUSIONS}

This paper introduces the theory of relational database firstly, On this foundation, puts forward the train of thought of life and service $\mathrm{O} 2 \mathrm{O}$ e-commerce platform logic structure design, and then designed of $\mathrm{O} 2 \mathrm{O}$ e- commerce platform for the external interface implementation detailed, realizated website architecture thought preliminary, It is a good try of $\mathrm{O} 2 \mathrm{O}$ e-commerce platform construction. The research results have been successfully applied.

\section{REFERENCE}

[1] http://baike.baidu.com/view/6877349.htm.

[2] Li Hongjuan.B2B research and implementation of electronic commerce system [Master thesis . Daqing: Daqing Petroleum Institute, 2004

[3] Han Xiaolu electronic commerce website customer relationship management. [Master thesis. Dalian: Dongbei University of Finance and Economics, 2004

[4] Xiao Pan Huang Ping, based on the SQL language implementation efficacy relational database performance testing study of [J]. computer and digital engineering 2012.3 ( 2).

[5] Ren Qing Bai. Relation database based on domain ontology construction method study and practice. [Master thesis . Beijing: Beijing University of Posts and Telecommunications, 2009

[6] Chen Wenyu object-oriented relational database design [J]. Journal of University of Electronic Science 2002.1 ( 32).

[7] Qiu Zhiguo class SSL encryption algorithm attack. [Master thesis . Ji'nan: Shandong University, 2007 